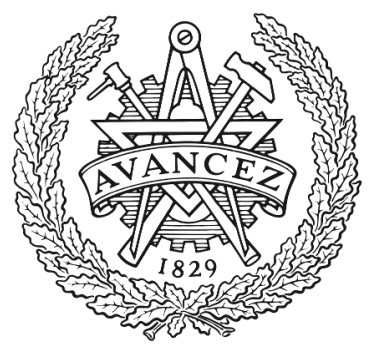

CHALMERS

UNIVERSITY OF TECHNOLOGY

\title{
A test platform of viable methods to improve production and learning on construction sites
}

Downloaded from: https://research.chalmers.se, 2023-04-25 23:37 UTC

Citation for the original published paper (version of record):

Simu, K., Räisänen, C., Erikshammar, J. (2019). A test platform of viable methods to improve production and learning on construction sites. Emerald Reach Proceedings Series: 481-487. http://dx.doi.org/10.1108/S2516-285320190000002049

N.B. When citing this work, cite the original published paper. 


\title{
A Test Platform of Viable Methods to Improve Production and Learning on Construction Sites
}

\author{
Kajsa Simu \\ Civil, Environmental and Natural Resources Engineering, \\ Lulea University of Technology, Luleä, Sweden \\ Christine Räisänen \\ Construction Management, Chalmers University of Technology, \\ Gothenburg, Sweden \\ Jarkko Erikshammar \\ Civil, Environmental and Natural Resources Engineering, \\ Lulea University of Technology, Luleå, Sweden
}

\begin{abstract}
Purpose - A comprehensive intervention test platform, Valla Coach, including quantitative and qualitative methods to measure and improve work flows on site and promote coaching and collective learning has been developed jointly by researchers and practitioner. The study aims to describe the methodological underpinning of the platform, and discusses the preliminary results and implications.

Design/Methodology/Approach - Expansive Learning Theory grounded in a cultural-historical perspective underpins the conceptual realisation of the test platform. The viability of the platform was tested in four contextually different construction sites (and contractors), combining established and new measurement tools, qualitative intervention approaches and coaching according to the production challenges at hand.

Findings - Valla Coach created a space on site where researchers-as-coaches and operatives converged to co-construct (new) knowledge and learn together. The knowledge that emerged from the interactions gained legitimacy through its situatedness and practical value for the operatives.

Research Limitations/Implications - Valla Coach provides opportunities for researchers and practitioners to probe the taken-for-granted. Moreover, a variety of methods and tools are tested in different contexts. The interventions prompt questioning of assumptions and make contradictions visible. Valla Coach remains work-in-progress and needs further evaluation and validation.

Practical Implications - We contribute insights from negotiating socio-technical complexities, evaluating digital measurement tools and technologies and experiences of operatives. Tensions at the interface between the organisation and project are rendered visible.
\end{abstract}

(C) Kajsa Simu, Christine Räisänen, Jarkko Erikshammar. Published in the Emerald Reach Proceedings Series. Published by Emerald Publishing Limited. This article is published under the Creative Commons Attribution (CC BY 4.0) licence. Anyone may reproduce, distribute, translate and create derivative works of this article (for both commercial and non-commercial purposes), subject to full attribution to the original publication and authors. The full terms of this licence may be seen at http://creativecommons.org/licences/by/4.0/legalcode

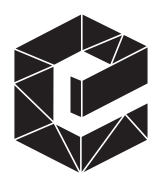

Emerald Reach Proceedings Series Vol. 2 pp. $481-487$ Emerald Publishing Limited DOI 10.1108/S2516-285320190000002049 
10th Nordic Conference Tallinn
Originality/Value - A bottom-up approach that is a combination of practice-based tools and methods and of theories of learning and sustainable and continuous improvements where the operators are the main actors that enable productive activity.

Keywords Expansive learning, On-site production, Test platform, Coaching, Continuous improvement, Standardization

All papers within this proceedings volume have been peer reviewed by the scientific committee of the 10th Nordic Conference on Construction Economics and Organization (CEO 2019).

\section{Introduction}

Mainstream project management literature seldom gives interpretative priority to social processes that underpin day-to-day activities in the projects. Indeed, there is little place for human agency in this research, which is an odd absence for a sector in which operatives take pride in their craftsmanship and responsible autonomy (Sandberg et al., 2016). Recently, there have been calls for practice-based research focusing on the lived experiences of project members (Blomquist et al., 2010) and at the interfaces of the projects and the organization (Löwstedt and Räisänen 2018). To achieve continuous improvements in the construction industry, there is a need not only to engage the interfaces of the organisation, but also to involve the operatives on-site in the design of the improvements. Then, instructions and standards would likely be better followed than is currently the case (Mariz et al., 2012). Co-construction of work specifications would ensure that explicit (formal) knowledge and tacit (experiential) knowledge are negotiated, and that the operatives feel ownership of the specifications they work by.

The construction industry has long adhered to a belief in the uniqueness of each project, overlooking possibilities and needs of standardisation (Mariz et al., 2012). In the design phase, detailed construction solutions are provided, but there is much freedom regarding implementation. Decisions are left to the site managers and foremen, resulting in local, ad-hoc practices with large varieties in quality, productivity and safety. To streamline practices in line with lean thinking, platforms have been designed to standardize work and facilitate knowledge transfer. However, most often, such platforms are designed at executive level and imposed on project level, resulting in resistance among operatives.

Standardisation of work activities is a baseline for improving processes and flows, but relevant data and information are critical. In industry parlance "you can't manage it if you can't measure it"! Therefore, accurate measurements and robust methods and tools fitted to the objects and motives at hand are imperative. To date, measures in construction focus primarily on bottom-line metrics rather than targeted measurements of activities that unfold on production sites. As improvement work in construction is challenging, it tends to a large extent to be isolated adjustments rarely transmitted to a larger context. This results in suboptimisation and waste. Lack of unified ways of working is a large cause of productivity deficits; others are barriers hindering knowledge transfer (Josephson and Saukkoriipi, 2009) and inadequate communication (Perumal and Bakar, 2011) regarding the specifications they are required to follow.

We believe that improvements of processes and flows would result in more stable implementation and learning if operatives were involved in the improvement design. Following this belief, an interdisciplinary collaborative endeavour was initiated, comprising three academic institutions and four construction companies, the aim being to develop an intervention methodology - including quantitative and qualitative methods - to enhance productivity, performance and learning on site. The vision was a mobile test platform, metaphorically named Valla Coach (i.e. Ski-waxing Coach), which would function as 
lubricant, both technically and pedagogically, to stimulate reflections on and enactments of processes and production flow improvements on site. We followed a three-step process: (1) evaluate different quantitative and qualitative methods for rapid assessment of current conditions and needs; (2) test existing and new digital measuring technologies in situ; and (3) coach teams and encourage expansive learning toward continuous improvement. To date, these steps have been carried out jointly with production operatives at four different construction sites with encouraging outcomes. This paper describes the methodology that underpins the development of Valla Coach and reports preliminary results. The paper contributes a viable approach to continuous improvement in construction and discusses implications of actively involving the operative level in the design of improvement work.

\section{Methodological underpinning for a learning test platform}

The development of Valla Coach is grounded on the cultural-historical Expansive Learning theory formulated by Engeström (1987; 2016). Expansive Learning has been used, tested and validated in various industrial workplaces, but remains fairly unknown in the construction-management literature. One of the few studies using an expansive-learning lens is that of Klitgaard et al. (2016), who examined learning in projects, concluding that fixed project goals hinder expansive learning. The authors asserted that "learning stemming from projects will be limited to learning by acquisition and participation" (ibid. p. 715). We query the claim, and argue that expansive learning in projects needs further testing before being dismissed.

We focus on how human beings can collectively by means of tools adapt to and change their environment and performance. It is precisely this interaction between individuals, tools and context that we seek to explore, explain and possibly improve through Valla Coach interventions. Tools, e.g. specifications and standards, are interesting because they constitute possibilities for action, and are in turn constituted by these actions. Consequently, as well as problematically, the tools stipulated at strategic level are often modified or even ignored by operatives in local contexts of use (Gluch and Räisänen 2009). This creates contradictions.

For improvements to prevail, contradictions need to first and foremost be rendered visible, hence Step 1 of the Valla Coach methodology: rapid assessment of site conditions. The motives of an activity encompasses more than the proverbial predetermined, fixed project goal. Motive or 'object', as viewed by Engeström (2016) encapsulates possibilities of shifting the goal through collaborative dialogic (re)creation of its meaning to accommodate new knowledge. For this to occur the goal of the activity needs to be "alive"; it needs to be reflected upon continuously and collectively.

Therefore, a prerequisite for improving production and performance is a learning culture that probes root causes and questions underpinning assumptions and beliefs, motives and goals. This kind of learning needs to transcend vertical and horizontal boundaries. Traditional ways of learnings most often involve learning what others already know, i.e. learning through acquisition and participation. However, such rote learning rarely results in lasting improvements or change.

Expansive learning, in contrast, is predicated on learning in situations where no one knows exactly what needs to be learned. Such learning is cyclic, consisting of seven iterated actions (Figure 1a) involving a collective learning-by-doing process mediated by human and non-human agents. What gets transformed in this process is the motive and goal of the activity itself rather than the individuals. The triggers of such transformative learning are the hidden contradictions, which are made visible through a process of interrogation leading to knowledge expansion and collective re-conceptualisation of the activity and practice. 
10th Nordic Conference Tallinn

\section{4}

Figure 1.

(a) Expansive Learning Actions (b) VALLA Coach Project

A transformation from acquisition and participation types of learning to expansive learning needs to be facilitated and encouraged in organisations by committed managers. The kind of learning mind-set promoted in an organization, in our view defines its culture as much as do its code of conduct and ways of working. Therefore, Valla Coach has been developed as both a facilitation and test platform tailored to bolster participants' agency in designing and effectuating change through a coaching attitude.

The four partner companies, two large contractors and two medium-size contractors, one of which is an industrialised housing contractor, provided testbed projects for trial runs of the Valla concept (Figure 1b). A steering group of company representatives framed the problem area and proposed intervention sites (the receptacle/core of the flower representation in Figure 1b). The intervention design was the remit of the researcher-ascoaches and site managers in the testbeds (petals Figure 1b). The coaches acted as knowledge brokers in the testbed, between the testbed and core (see arrows in Figure 1b) and between the four partner companies.

\section{Results: The Valla Coach platform}

Here, we describe the methods tested so far beds and some outcomes. The methods are geared toward enabling the seven actions of the expansive learning cycle, see Figure 1a. The main criterion for the methods chosen in the trial runs was that the researchers had previous experience and knowledge about their usage in other industries. The methods are sorted in three main categories.

\subsection{Assessing current situation - defining baseline}

These methods serve to prompt Actions 1 and 2 of the expansive-learning cycle.

Rapid site assessment (RSA). RSA originated from the Read-a-Plant-Fast (Goodson, 2002) developed to enable rapid evaluation of a plant's status quo. The method consists of three steps: preparations, site visit and evaluation. We found that RSA or an adaptation thereof provided us with important "first impressions" and a preliminary documented status quo. We also found that this method requires meticulous background research and planning prior to the site visit. RSA can be used to prioritise specific areas and activities of improvement, to benchmark projects or to rapidly assess subcontractors.

Time studies. To manage time efficiently requires informed and objective time measurements. Traditional manual time-taking combined with digital video cameras have enabled us to analyse work sequences and evaluate value and non-value-adding actions.

(a)

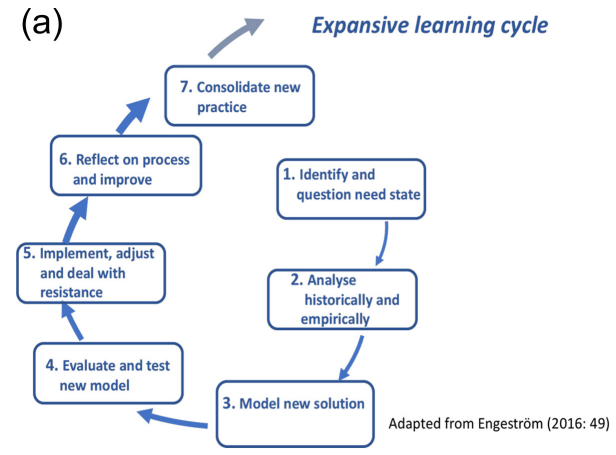

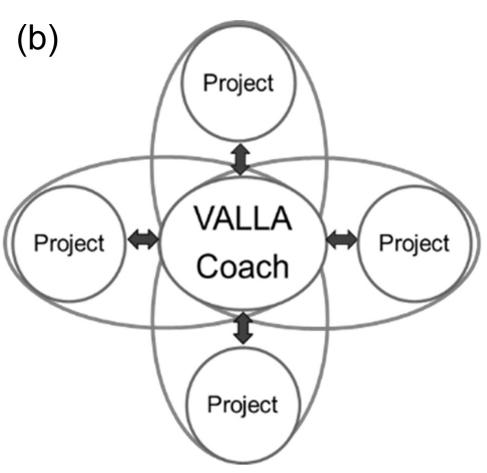


Involving site workers in the analyses of outcomes raised both their and the coaches' awareness of specific obstacles and possibilities as these unfolded. To advance time measurements on site, we initiated a collaboration with a developer of novel digital solutions (Zhao, Olivieri et al., 2017), and are currently testing one of these in a testbed. Early results from observations are slack in the timetable and opportunities to reduce lead time up to 50 per cent. We continue to develop awareness and techniques for relevant time studies as it is the baseline for most improvements.

Focus groups. To create deeper understanding of organizational history and sedimented practices, focus groups (Räisänen and Gunnarson, 2004) were used to assess current states as well as to reflect over process (Actions 1,2 and 6; Fig. 1a), zooming in on issues of contention, i.e. contradiction. We found that focus groups provided a 'neutral' forum for reflection since they were facilitated by external experts. Hidden frustrations and tensions at the interface between strategic and operational levels were brought to the surface, forcing participants to address taken for granted assumptions. This outcome supports the call for more research at the interfaces of the organizations (Löwstedt and Räisänen 2018), and we are developing scenarios to facilitate negotiation.

On-site observations and manual protocols. To assess the practical use and misuse of standards, observation protocols provide a structured feedback and analysis tool. They are collective anchor points for on-site observations and focus attention on critical aspects of standard use. We devised tailor-made protocols based on task specifications for a module assembly. We observed sequential module assemblies on several occasions, and recorded deviations from specifications. We then debriefed the operatives at the end of the task. We found that protocols were valuable boundary object for discussion of moot points. This resulted in a questioning of the specifications and collaborative revisions with operatives as well as testing of the revised specifications. Moreover, debriefing the operatives directly after the activity provided detailed feedback to the specification designers.

\subsection{Category 2: improving process flow and operational stability}

The following method serves to facilitate Actions 3-6 in the learning cycle by creating visual boundary object to support collaboration through dialogic co-construction.

Last planner - for planning and execution of plans on site. The last planner system (LPS) is a visual project-planning method designed to engage and commit all project members (Ballard, 2000). Two full-day workshops were allocated to sharing knowledge and experience of LPS implementations in the four partner organisations. Challenges were how to best measure and follow up on flows rather than only focus on utilisation of resources. The managerial levels of the partner organisations had difficulties "proving" efficiency gains of LPS-like methods. Another challenge was how to convert from analogue to digital set-up. Both workshops resulted in raising awareness of the need to exert effort on changing people's attitudes by working bottom-up, rather than top down, supporting the need for learning test platforms. More importantly, the workshops enabled competitive partners to openly share and benefit from each other's successes and failures.

\subsection{Category 3: standards toward work stability}

This category of methods encompasses all the actions of the expansive-learning cycle and involves safety aspects in a production process, i.e. how to implement, test and develop each part of the production flow. For this, the key is involvement of all the skilled workers to identify what needs to be done and how it should best be done. Our work in the testbeds and the workshops has shown that there is a lack of knowledge and experience around standardization work. 
10th Nordic Conference Tallinn
Coaching as facilitation method. Coaching is a well-known intervention in leadership development and can be seen as a work-related learning approach. A coach's job is to "unlock people's potential to maximise their own performance" (Whitmore, 2009:10), i.e. create a trustful and caring atmosphere that allows probing of assumptions. The Valla coaches paid attention to the site workers as these carried out their activities, and simultaneously empowered them to question actions, rules and norms. Coaches encouraged operatives to take responsibility for the way the activity developed by listening actively, providing prompts in the form of open questions, and ensuring there was common understanding. Consciously adopting a coaching attitude increased operatives' trust and willingness to share their know-how; most importantly, it enhanced mutual learning. The learning the coaches take away from the testbeds is invaluable for further development and fine-tuning of Valla Coach.

Workplace standard and operational work. To enhance standards, it is necessary to know the context of the work, how to break up a task into work moments and to identify possible pitfalls. Even though the partner companies had standards, these were often circumvented. Thus, coaches focused on stimulating collaborative work between strategic and operational teams, following the seven epistemic actions (Figure 1a). We found that foremen and site personnel were keen to actively take part in work improvements, which supports studies suggesting that worker engagement drives ROI and performance (Gruman and Saks, 2011). The testbeds trials so far have shown that there is a lack of knowledge and experience around standardization work. This in turn results in descriptive rather than explanatory standards that lack rationale and followup measures.

\section{Conclusions}

Valla Coach is, to date, work-in-progress carried out jointly by researchers and practitioners working toward ways of improving production and performance in construction companies through a bottom-up process. The purpose of this paper has been to illustrate how such a process can be achieved. The findings so far are encouraging and show that there is a need for this kind of learning platform. Through coaching interventions and collaborative testing of a variety of methods at different construction sites, both old and new methods can be finetuned to capture problem areas and hidden contradictions.

In our work so far, we have seen that in spite of the existence of metrics and the willingness of operative personnel to improve their performance, there is a lack of structured, systematic ways of relating the metrics to performance standards. Thus, directions and goals for improvement remain unclear, creating frustration at all levels as well as resistance to topdown work-practice decisions and specifications. The learning that does take place may improve production in discreet projects, but seldom benefits the organization as a whole. Digitalisation would enable data to be captured, structured and analysed, but first people must be willing to learn and improve their work on a daily basis enabled by viable processes and standards. Valla Coach grounded on an expansive learning methodology has shown so far to be a viable and sound process.

Our ambition is to facilitate systematic and continuous improvements through relevant and tailored standards that make sense to those who use them, and to expand our own learning in the process. The challenges to come include validation of and at the same time train coaches in the methods and tools included in the platform. This will in practice show how well expansive learning works in construction business. 


\section{References}

Ballard, H.G. (2000), The last planner system of production control, University of Birmingham.

Blomquist, T., Hällgren, M., Nilsson, A. and Söderholm, A. (2010), "Project-as-practice: in search of project management research that matters", Project Management Journal, Vol 41 No 1, pp. 5-16.

Engeström, Y. (1987), "Learning by expanding: An activity-theoretical approach to developmental research", Orienta-Konsultit, Helsinki.

Engeström, Y. (2016), Studies in Expansive Learning: Learning What is Not There Yet, Cambridge University Press, Cambridge.

Gluch, P. \& Räisänen, C. (2009) "An interactional perspective on environmental communication in construction projects", Building Research and Information, Vol 37 No 2, pp. 164-175.

Gruman, J.A. and Saks, A.M. (2011), "Performance management and employee engagement", Human Resource Management Review, Vol 21 No 2, pp. 123-136.

Josephson, P. and Saukkoriipi, 1. (2009), 31 rekommendationer för ökad lönsamhet i byggandet - att minska slöseriet.

Klitgaard, A., Nissen, S. B., Beck, F., Jeppesen, R. D., Buhl, H. (2016), "Expansive learning in construction projects - A contradiction in terms?", in Chan, P. and Neilson, C. (Eds.), Proceedings of the 32nd Annual ARCOM Conference, Manchester UK, pp. 709-717.

Löwstedt, M. and Räisänen, C. (2014), "Social identity in construction: Enactment and Outcomes", Construction Management and Economics, Vol 32 No 11, pp. 1,093-1,105.

Mariz, R.N., Picchi, F.A., Granja, A.D. and Melo, R., (2012) "A review of the standardized work application in construction", Proceedings of the 20th annual conference of the international group for lean construction.

Perumal, V.R. and Bakar, A.H.A., 2011. "The needs for standardization of document towards an efficient communication in the construction industry", Acta Technica Corviniensis-Bulletin of engineering, 4(1), pp. 23.

Räisänen, C \& Gunnarson, S. 2004. "Multi-project organisations from a methodological perspective", IRNOP IV Proceedings Turku, Finland, pp. 252-265. Åbo: Åbo Akademi University Press.

Sandberg, R., Raiden, A. and Räisänen, C. (2016), “Workaholics on site! Sustainability of site managers' work situation”, CIB World Building Congress", May 30-June 32016 , Tampere, Finland.

Whitmore, J. (2009) "Coaching for performance: GROWing human potential and purpose", London: Nicholas Brealy Publ.

Zhao, J., Olivieri, H., Seppanen, O., Peltokorpi, A., Badihi, B. and Lundstrom, P., (2017), "Data analysis on applying real time tracking in production control of construction", Proceedings of the IEEE International Conference on Industrial Engineering and Engineering Management, pp. 573-577. 